\title{
Provision of Palliative Care Services by Family Physicians Is Common
}

\author{
Claire K. Ankuda, MD, MPH, Anuradha Jetty, MPH, Andrew Bazemore, MD, MPH, \\ and Stephen Petterson, $\mathrm{PhD}$
}

Objective: Provision of palliative care services by primary care physicians is increasingly important with an aging population, but it is unknown whether US primary care physicians see themselves as palliative practitioners.

Methods: This study used cross-sectional analysis of data from the 2013 American Board of Family Medicine Maintenance of Certification Demographic Survey.

Results: Of 10,894 family physicians, $33.1 \%(n=3609)$ report providing palliative care. Those providing palliative care are significantly more likely to provide non-clinic-based services such as care in nursing homes, home visits, and hospice. Controlling for other characteristics, physicians reporting palliative care provision are significantly $(P<.05)$ more likely to be older, white, male, rural, and practicing in a patient-centered medical home.

Conclusion: One third of family physicians recertifying in 2013 reported providing palliative care, with physician and practice characteristics driving reporting palliative care provision.(J Am Board Fam Med 2017;30:255-257.)

Keywords: Certification; Cross-Sectional Studies; Delivery of Health Care; Demography; Geriatrics; Hospice Care; Hospices; House Calls; Nursing Homes; Palliative Care; Physicians, Family; Primary Care Physicians

Between 2015 and 2030, the number of older adults in the United States will grow from 46 million to 69 million. $^{1}$ This "silver tsunami" will challenge outpatient primary care, the nation's largest health care delivery platform, ${ }^{2}$ with unprecedented levels of chronic illnesses. ${ }^{3}$ Medical advances will create for many of these patients a prolonged trajectory of dying ${ }^{4}$ in which primary care physicians will play critical roles in care coordination and front-line management.

\footnotetext{
This article was externally peer reviewed.

Submitted 18 July 2016; revised 18 November 2016; accepted 30 November 2016.

From the Robert Wood Johnson Clinical Scholars Program and the Department of Family Medicine, University of Michigan, Ann Arbor (CKA); and the Robert Graham Center, Washington, DC (AJ, AB, SP).

Funding: CKA is funded by the Robert Wood Johnson Foundation.

Conflict of interest: none declared.

Corresponding author: Claire K. Ankuda, MD, MPH, Robert Wood Johnson Foundation Clinical Scholars Program, University of Michigan, NCRC, 2800 Plymouth Rd, Bldg 14, Rm G100, Ann Arbor, MI 48109-2800 (E-mail: cankuda@umich.edu).
}

Simultaneously, palliative care, which focuses on addressing quality of life, has shifted its focus from end-of-life care to care along the trajectory of illness. ${ }^{5}$ It is unclear how many primary care physicians see themselves as providers of palliative care in general practice.

\section{Methods}

The data source was the 2013 American Board of Family Medicine (ABFM) Maintenance of Certification Demographic Survey. This is a required survey for family physicians applying for recertification exams. The primary outcome measure was whether the examinee indicated they provided palliative care from among a range of practice services queried. Rates of reported palliative care provision were compared between physicians based on palliative-specific practices (nursing home care, home visits, and hospice care) and demographic and practice characteristics. Logistic regression was used to estimate the odds of reporting palliative provision associated with clinical practices consistent with palliative care (hospice, nursing home, and home 
Table 1. Characteristics of American Board of Family Medicine Diplomates Providing Palliative Care

\begin{tabular}{|c|c|c|c|}
\hline \multirow[b]{2}{*}{ Characteristics (n) } & \multirow[b]{2}{*}{ Diplomates (n) } & \multicolumn{2}{|c|}{ Provides Palliative Care } \\
\hline & & Diplomates, n (\%) & OR $(95 \% \mathrm{CI})$ \\
\hline All & 10,894 & $3,609(33.13)$ & \\
\hline \multicolumn{4}{|l|}{ Palliative-specific practices } \\
\hline Routinely see patients in hospice & 733 & $616(84.04)$ & $5.77(4.62-7.19)^{*}$ \\
\hline $\begin{array}{l}\text { Routinely see patients in nursing } \\
\text { home }\end{array}$ & 1,641 & $1,086(66.20)$ & $3.40(3.05-3.80)^{*}$ \\
\hline Routinely makes home visits & 2,474 & $1,609(65.04)$ & $2.36(2.07 \text { to }-2.69)^{*}$ \\
\hline $\begin{array}{l}\text { Certified in hospice and palliative } \\
\text { medicine }\end{array}$ & 241 & $227(94.19)$ & \\
\hline \multicolumn{4}{|l|}{ Sex } \\
\hline Male & 6,891 & $2,475(35.92)$ & Reference \\
\hline Female & 4,003 & $1,134(28.33)$ & $0.96(0.87-1.06)^{*}$ \\
\hline \multicolumn{4}{|l|}{ Region of practice } \\
\hline South & 3,687 & $1,088(29.51)$ & Reference \\
\hline Northeast & 1,579 & $558(35.34)$ & $1.07(0.93$ to -1.24$)$ \\
\hline West & 2,661 & $856(32.17)$ & $1.16(1.03 \text { to }-1.32)^{\dagger}$ \\
\hline Midwest & 2,942 & $1,100(37.39)$ & $1.07(0.95$ to -1.21$)$ \\
\hline \multicolumn{4}{|l|}{ Race } \\
\hline White & 8,743 & $3,172(36.28)$ & Reference \\
\hline Black & 659 & $99(15.02)$ & $0.36(0.28 \text { to }-0.46)^{*}$ \\
\hline Asian & 1,300 & $287(22.08)$ & $0.62(0.53-0.73)^{*}$ \\
\hline Other & 192 & $51(26.56)$ & $0.67(0.47 \text { to }-0.96)^{\dagger}$ \\
\hline \multicolumn{4}{|l|}{ Years in practice } \\
\hline $0-10$ & 2,983 & $811(27.20)$ & Reference \\
\hline $11-20$ & 3,461 & $1,076(31.09)$ & $1.17(1.04 \text { to }-1.32)^{\dagger}$ \\
\hline $21-30$ & 3,278 & $1,242(37.89)$ & $1.32(1.70 \text { to }-1.50)^{*}$ \\
\hline$\geq 31$ & 1,171 & $479(40.91)$ & $1.36(1.15 \text { to }-1.60)^{*}$ \\
\hline \multicolumn{4}{|l|}{ Ethnicity } \\
\hline Non-Hispanic & 10,258 & $3,452(33.65)$ & Reference \\
\hline Hispanic & 636 & $157(24.69)$ & $0.74(0.60-0.92)^{*}$ \\
\hline \multicolumn{4}{|l|}{ Rurality } \\
\hline Urban (population $>50,000$ ) & 9,079 & 2,662 (29.32) & Reference \\
\hline Population $20,000-50,000$ & 740 & $325(43.92)$ & $1.38(1.16 \text { to }-1.64)^{*}$ \\
\hline Population 2,500-19,999 & 926 & $524(56.59)$ & $2.05(1.75 \text { to }-2.40)^{*}$ \\
\hline Rural (population <2,500) & 149 & $98(65.77)$ & $2.38(1.61 \text { to }-3.50)^{*}$ \\
\hline \multicolumn{4}{|l|}{ Practice size } \\
\hline Large ( $>20$ providers) & 1,929 & $582(30.17)$ & Reference \\
\hline Medium (6-20 providers) & 3,382 & $1,106(32.70)$ & $1.02(0.89 \text { to }-1.17)^{*}$ \\
\hline Small (2-5 providers) & 3,902 & $1,342(34.39)$ & $1.06(0.93 \text { to }-1.22)^{*}$ \\
\hline Solo & 1,681 & $579(34.44)$ & $1.10(0.93 \text { to }-1.30)^{*}$ \\
\hline \multicolumn{4}{|l|}{ PCMH status } \\
\hline Neither applicant nor certified & 4,758 & $1330(36.90)$ & Reference \\
\hline PCMH applicant & 3,562 & $1,380(38.20)$ & $1.54(1.38 \text { to }-1.70)^{*}$ \\
\hline PCMH certified & 2,574 & $899(24.90)$ & $1.73(1.54 \text { to }-1.96)^{*}$ \\
\hline
\end{tabular}

Source: 2013 American Board of Family Medicine Maintenance of Certification Demographic Survey.

${ }^{*} P<.001$.

${ }^{\dagger} P<.05$.

$\mathrm{CI}$, confidence interval; OR, odds ratio; $\mathrm{PCMH}$, patient-centered medical home. 
visits) and individual physician demographic characteristics in Table 1 .

\section{Results}

A total of 10,894 ABFM recertification examination enrollees completed the demographic survey in 2013. One third of respondents reported providing palliative care. As predicted, odds of reporting palliative care provision were higher for those physicians seeing patients in hospices, nursing homes, and during home visits. Greater odds of reporting palliative care provision were seen among rural versus urban physicians (odds ratio [OR], 2.38; 95\% confidence interval [CI], 1.61-3.50); west versus south region (OR, 1.16; 95\% CI, 1.03-1.32); and patient-centered medical home (PCMH) certification (OR, 1.73; 95\% CI, 1.54-1.96) or PCMH applicants (OR, 1.54; 95\% CI, 1.38-1.70) versus those not applying or certified for PCMH credentials. Odds of reporting palliative care provision was less among black versus white physicians (OR, 0.36; 95\% CI, 0.28-0.46), Asian American versus white physicians (OR, 0.62; 95\% CI, 0.53-0.73), and Hispanic versus non-Hispanic physicians (OR, 0.74; 95\% CI, 0.60-0.92). Odds of reporting palliative care provision were greater for physicians in practice $>30$ versus $<10$ years (OR, 1.36 ; $95 \% \mathrm{CI}$, $1.15-1.60)$.

\section{Discussion}

One third of family physicians recertifying in the ABFM Maintenance of Certification in 2013 see themselves as palliative care providers, although this varies regionally, by physician demographics, and by clinic settings. It is concerning that physicians reporting that they provide palliative care are more likely to be older, white, male, and rural, as this may limit patients' access to primary palliative care. However, it is reassuring that those with or pursuing $\mathrm{PCMH}$ certification are more likely to report palliative care provision given the current policy emphasis on supporting PCMHs.

This study used a broad, self-reported question of whether physicians provide palliative care in their routine practice and is therefore limited by self-reporting bias and potential ambiguity in the interpretation of palliative care by respondents. Further work needs to be done to understand the degree and quality of palliative care provided by family physicians. Our data source had the advantage of being a required survey for recertifying physicians, capturing responses from approximately $10 \%$ of all family physicians.

This study raises questions about what family physicians perceive as their role in providing palliative care and what they need in order to better engage in palliative care. Future work is needed to understand the barriers to providing palliative care for family physicians.

To see this article online, please go to: http://jabfm.org/content/ 30/2/255.full.

\section{References}

1. Ortman JM, Velkoff VA, Hogan H. An aging nation: the older population in the United States. Population estimates and projections. May 2014. Available from https://www.census.gov/prod/2014pubs/p251140.pdf. Accessed January 19, 2017.

2. Green LA, Fryer GE, Yawn BP, Lanier D, Dovey S. The ecology of medical care revisited. N Engl J Med 2001;344:2021-5.

3. Colwill JM, Cultice JM, Kruse RL. Will generalist physician supply meet demands of an increasing and aging population? Health Aff (Millwood) 2008;27: w232-41.

4. Lynn J. Living long in fragile health: the new demographics shape end of life care. Hastings Cent Rep 2005;Spec No:S14-8.

5. Lynn J, Adamson DM. Living well at the end of life: adapting health care to serious chronic illness in old age. Santa Monica, CA: Rand Corporation; 2003. Available from http://www.rand.org/pubs/white_ papers/WP137.htm. Accessed January 19, 2017. 